\title{
Transdiaphragmatic pressure and neural respiratory drive measured during inspiratory muscle training in stable patients with chronic obstructive pulmonary disease
}

\author{
This article was published in the following Dove Press journal: \\ International Journal of COPD \\ 2 March 2017 \\ Number of times this article has been viewed
}

\author{
Weiliang $\mathrm{Wu}^{\prime}$ \\ Xianming Zhang ${ }^{2}$ \\ Lin Lin' \\ Yonger $\mathrm{Ou}^{\prime}$ \\ Xiaoying $\mathrm{Li}^{\prime}$ \\ Lili Guan' \\ Bingpeng Guo' \\ Luqian Zhou' \\ Rongchang Chen'
}

'State Key Laboratory of Respiratory Disease, Guangzhou Institute of Respiratory Disease, The First Affiliated Hospital of Guangzhou Medical University, Guangzhou, ${ }^{2}$ Department of Respiratory Medicine,

The First Affiliated Hospital of

Guizhou Medical University, Guizhou,

People's Republic of China
Correspondence: Luqian Zhou;

Rongchang Chen

State Key Laboratory of Respiratory

Disease, Guangzhou Institute of

Respiratory Disease, The First Affiliated

Hospital of Guangzhou Medical University,

I5I Yan Jiang Road, Guangzhou 510000,

People's Republic of China

Tel +86 I37 6338 3। 60 ;

+86 I58 20243582

Fax +86 2083062882

Email zhlx09@163.com;

chenrc_vip@I63.com
Purpose: Inspiratory muscle training (IMT) is a rehabilitation therapy for stable patients with COPD. However, its therapeutic effect remains undefined due to the unclear nature of diaphragmatic mobilization during IMT. Diaphragmatic mobilization, represented by transdiaphragmatic pressure (Pdi), and neural respiratory drive, expressed as the corrected root mean square (RMS) of the diaphragmatic electromyogram (EMGdi), both provide vital information to select the proper IMT device and loads in COPD, therefore contributing to the curative effect of IMT. Pdi and RMS of EMGdi (RMSdi\%) were measured and compared during inspiratory resistive training and threshold load training in stable patients with COPD.

Patients and methods: Pdi and neural respiratory drive were measured continuously during inspiratory resistive training and threshold load training in 12 stable patients with COPD (forced expiratory volume in $1 \mathrm{~s} \pm \mathrm{SD}$ was $26.1 \% \pm 10.2 \%$ predicted).

Results: Pdi was significantly higher during high-intensity threshold load training (91.46 $\left.\pm 17.24 \mathrm{cmH}_{2} \mathrm{O}\right)$ than during inspiratory resistive training $\left(27.24 \pm 6.13 \mathrm{cmH}_{2} \mathrm{O}\right)$ in stable patients with COPD, with $P<0.01$ for each. Significant difference was also found in RMSdi\% between high-intensity threshold load training and inspiratory resistive training $(69.98 \% \pm 16.78 \%$ vs $17.26 \% \pm 14.65 \%, P<0.01)$.

Conclusion: We concluded that threshold load training shows greater mobilization of Pdi and neural respiratory drive than inspiratory resistive training in stable patients with COPD.

Keywords: diaphragmatic electromyogram, inspiratory threshold load training, inspiratory resistive training, pulmonary rehabilitation, respiratory physiological detection

\section{Introduction}

Inspiratory muscle training (IMT) is an effective treatment modality in COPD patients to improve respiratory muscle strength and endurance, resulting in improvement of dyspnea, functional exercise capacity, and quality of life. ${ }^{1}$ The American Respiratory Society/European Respiratory Society statement suggests that IMT be mainly applied to stable patients with COPD with suspected or specific inspiratory muscle weakness. ${ }^{2}$ Weakness of the diaphragm and the accessory muscle of inspiration is universally found in patients with long-duration COPD. ${ }^{3}$ Weakness of inspiratory muscle results in dyspnea ${ }^{4}$ and decrease of exercise tolerance, ${ }^{5}$ as well as hypoxemia, in patients with COPD. ${ }^{6}$

IMT is supposed to increase inspiratory muscle strength and endurance, decrease dyspnea, as well as improve exercise capacity and the quality of life. ${ }^{7}$ It is defined as 

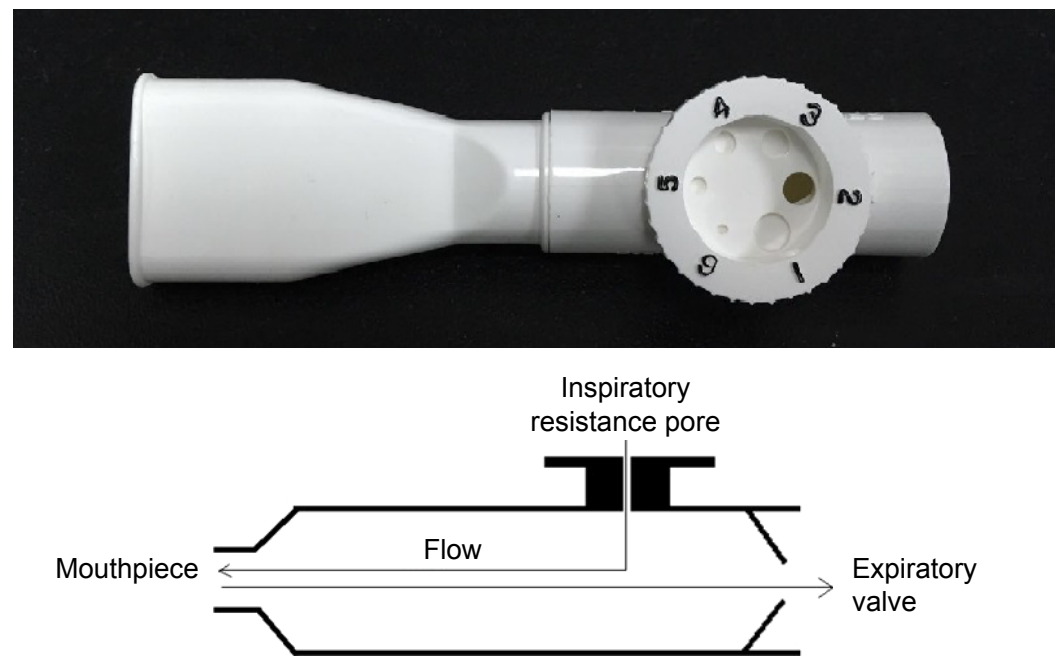

Figure I Respiratory resistance device (PFLEX; Respironics Inc; Pittsburgh, PA, USA).

the continuous training of inspiratory muscular strength using an inspiratory trainer. ${ }^{2}$ However, the therapeutic effect of IMT remains undefined due to the diversity of IMT devices and loads. Various devices and loads arouse different diaphragmatic mobilizations (represented by diaphragmatic pressure and neural respiratory drive). Furthermore, sufficient diaphragmatic mobilization is the key point of securing the training effect. ${ }^{8}$ However, diaphragmatic mobilization during various IMT devices and loads has not been researched in previous studies.

Inspiratory muscle trainers are classified into inspiratory resistive trainers (Figure 1) and inspiratory threshold trainers (Figure 2) according to their operation principle. The built-in spring-loaded valve of the threshold trainer provides a constant, predetermined inspiratory load that is maintained during the entire inspiratory phase. Inspiratory resistive trainers do not provide a constant inspiratory load to ensure the attainment of the inspiratory training intensity. ${ }^{9}$ The operation principles of the two inspiratory muscle trainers have great differences. Inspiratory resistance that is generated by inspiratory resistive trainers is based on the inspiratory flow rate. But threshold load is independent of flow inspiratory rate. ${ }^{7}$ The two IMT devices apply low-, moderate-, and high-intensity loads. Various IMT devices and loads arouse different levels of diaphragmatic mobilization.

Diaphragmatic mobilization during the IMT is directly vital to the curative effects. ${ }^{10}$ However, diaphragmatic mobilization expressed as transdiaphragmatic pressure (Pdi) and the neural respiratory drive during the IMT have not been described in previous studies. It is necessary to evaluate Pdi and neural respiratory drive during IMT. Pdi represents the diaphragmatic power output as a mechanical signal.
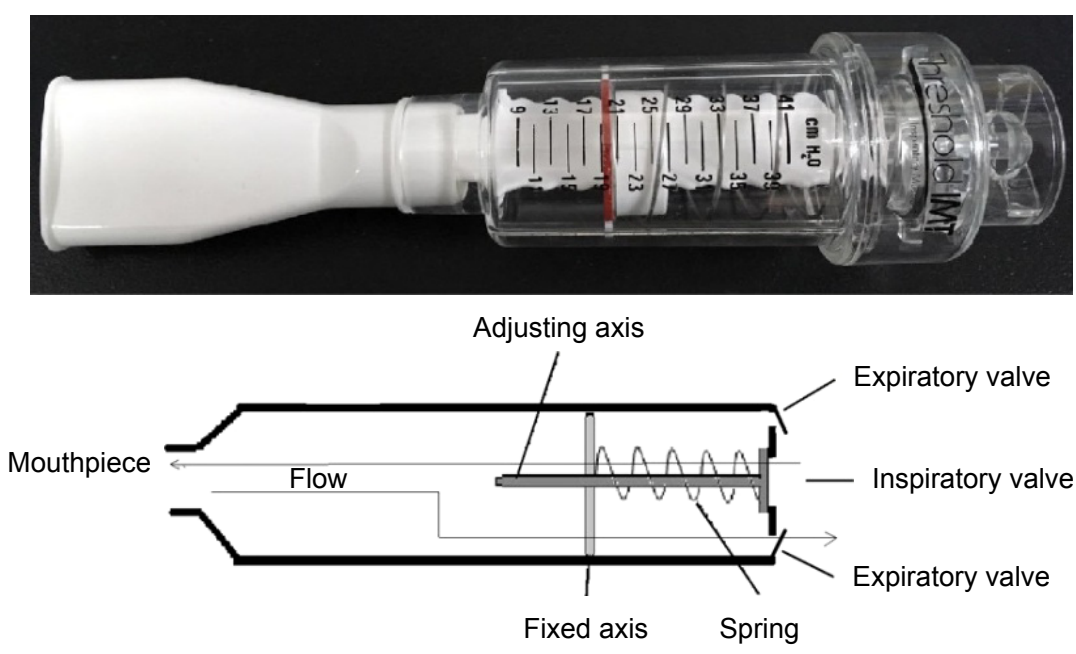

Figure 2 Respiratory threshold load device (Threshold Inspiration Muscle Trainer; Respironics Inc; Pittsburgh, PA, USA). 
Neural respiratory drive represents the inspiratory effort as an electrical signal. Neural respiratory drive measured by the diaphragmatic electromyogram (EMGdi) provides a sensitive real-time breath-by-breath measure of neural respiratory drive, which reflects the load on the respiratory muscles. ${ }^{8}$

We hypothesize that higher-intensity flow-independent inspiratory threshold trainers arouse sufficient diaphragmatic mobilization in stable patients with COPD. The purpose of this study was to measure Pdi and neural respiratory drive during the use of various IMT devices (inspiratory resistive trainers and threshold load trainers) and loads (low, moderate, and high intensity) in COPD, further clarifying the proper device and loads that result in a reliable training effect.

\section{Patients and methods Subjects}

The diagnosis and severity of COPD in all participants were measured using the pulmonary function test, according to the Global Initiative for Chronic Obstructive Lung Disease (GOLD). ${ }^{1}$ Inclusion criteria included the following: 1) severe and very severe COPD (postbronchodilator forced expiratory volume in $1 \mathrm{~s}\left[\mathrm{FEV}_{1}\right] /$ forced vital capacity $[\mathrm{FVC}]<70 \%$ and $\mathrm{FEV}_{1}<50 \%$ of the predicted value) (GOLD C and $\mathrm{D}$ groups, respectively); 2) inspiratory muscle weakness (maximal inspiratory pressure $[\mathrm{MIP}]<60 \mathrm{cmH}_{2} \mathrm{O}$ ); and 3) bronchial dilation test (BDT) negative. Exclusion criteria included the following: 1) acute exacerbation in the previous 4 weeks; 2) use of oral corticosteroids within 4 weeks; and 3) history of other respiratory, cardiovascular, neuromuscular, and musculoskeletal diseases that could interfere with the study. Twelve stable patients with COPD of mean age (mean \pm SD) $61.8 \pm 10.3$ years and $\mathrm{FEV}_{1} 26.1 \% \pm 10.2 \%$ predicted were recruited in the study.

\section{Study design}

This was an observational, single-center, cross-sectional study. Our study has been reviewed and published on the ClinicalTrials.gov public site (identifier: NCT03017300). The study protocol was approved by the Ethics Committee of the First Affiliated Hospital of Guangzhou Medical College (approval number: 2015-4). Written informed consent was obtained from all subjects prior to study participation.

\section{Measurements of Pdi and mouth pressures}

The Pdi was calculated by subtraction of the esophageal pressure (Pes) from the gastric pressure (Pga), ie, $(\mathrm{Pdi}=\mathrm{Pga}-\mathrm{Pes})$. The Pes and Pga were measured by one double-lumen catheter separately opening into two latex balloons (Figure 3) respectively positioned $10 \mathrm{~cm}$ above the cardia and in the stomach. Furthermore, the two latex balloons were respectively filled with $0.5 \mathrm{~mL}$ and $1-2 \mathrm{~mL}$ of air. ${ }^{11}$ The mouth pressure (Pm) was measured by detecting the pressure in the mouthpiece. ${ }^{12}$ The mouthpiece and the two lumens of the catheter were respectively coupled to three pressure transducers (MLT844; ADInstruments, Bella Vista, NSW, Australia) that were

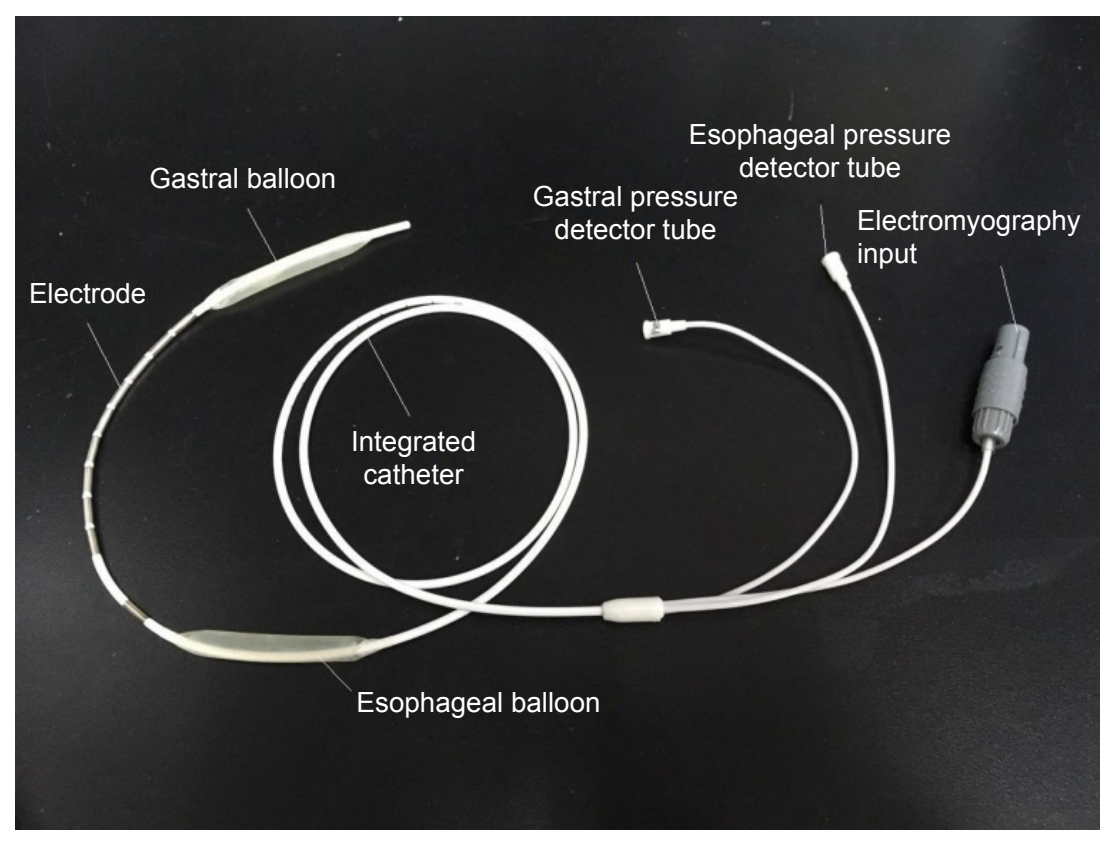

Figure 3 Multipair esophageal electrode with esophageal and gastric pressure balloons. 
connected to the biological signal acquisition and analysis system (Powerlab 16/35; ADInstruments) via a four-channel bridge amplifier (FE224; ADInstruments). The flow rate was obtained by using a pressure differential pneumotachograph (MLT300L; ADInstruments).

\section{Measurements of neural respiratory drive}

EMGdi is the classic measurement describing diaphragmatic myoelectric signals, the electrical manifestations of the excitation process elicited by action potentials propagating along muscle fiber membranes. The EMG signal is detected with electrodes and then amplified, filtered, and displayed on a screen or digitized to facilitate further analysis. Electromyography of respiratory muscles can be used to assess the level and pattern of their activation so as to detect and diagnose neuromuscular pathology and, when coupled with tests of mechanical function, to assess the efficacy of the muscle's contractile function. ${ }^{13}$

Neural respiratory drive, expressed as EMGdi, was measured using a multipair esophageal electrode consisting of nine consecutive coils composed of five electrode pairs ${ }^{14}$ positioned in the esophagus and traversing the cardia. ${ }^{15}$ (Figure 3 ).

EMGdi signals acquired with digital sampling at $2 \mathrm{kHz}$ were bandpass filtered $(10 \mathrm{~Hz}-3 \mathrm{kHz})$ and amplified. Peak root mean square (RMS) per respiratory cycle was calculated and averaged over $1 \mathrm{~min}$. RMS of the EMGdi signal is an index of the total EMGdi power. Theoretically, the RMS of the EMGdi reflects the force output of the diaphragm.

\section{MIP measurement}

MIP measurement is a widely used test of inspiratory muscle strength. The measurement of MIP reflects the strength generated by the entire set of inspiratory muscles. Patients were normally seated and strongly urged to make maximum inspiratory efforts at residual volume. The maximum pressure of the mouthpiece was measured during the maximal inspiratory maneuvers. The maximum value of three satisfactory manipulations that varied by $<20 \%$ was recorded. ${ }^{16}$

\section{Inspiratory resistive training}

All participants underwent inspiratory resistive training using inspiratory resistive trainer (PFLEX; Respironics Inc, Pittsburgh, PA, USA) (Figure 1). Pdi and EMGdi were recorded synchronously. ${ }^{14}$ Inspiratory resistive load was changed from low intensity into moderate and high intensities randomly (inspiratory hole diameters were set to $5.3 \mathrm{~mm}$, $2.4 \mathrm{~mm}$, and $1.8 \mathrm{~mm}$, respectively). ${ }^{17}$

\section{Inspiratory threshold load training}

Inspiratory threshold load training was performed by all participants using the inspiratory threshold load trainer (Threshold Inspiration Muscle Trainer; Respironics Inc) (Figure 2). Inspiratory threshold pressure was set to low, medium, and high intensities randomly (threshold pressure was $30 \%, 60 \%$, and $80 \%$ of MIP, respectively). Pdi and EMGdi were measured synchronously.

\section{Statistical analysis}

Statistical analysis was carried out using SPSS 20.0 (SPSS Inc, Chicago, IL, USA). All data are presented as the mean \pm standard deviation (mean $\pm \mathrm{SD}$ ). Comparison of the Pdi and RMSdi\% values between the two methods of training were evaluated using the paired $t$-test. Analysis of variance (ANOVA) was applied for multiple-group comparisons.

\section{Results}

Twelve stable patients with COPD of mean age (mean \pm SD) of $61.8 \pm 10.3$ years and $\mathrm{FEV}_{1}$ of $26.1 \% \pm 10.2 \%$ predicted were recruited in this study. Pdi was $23.21 \pm 3.29 \mathrm{cmH}_{2} \mathrm{O}$ and the neural respiratory drive expressed as RMSdi\% was $22.12 \% \pm 18.32 \%$ in spontaneous breathing.

Figure 4 shows an example of the respiratory mechanics recordings in spontaneous breathing, inspiratory resistive, and threshold load training.

Figure 5 shows a lower Pdi during spontaneous breathing than during inspiratory resistive and threshold load training. Pdi remained the same during each intensity level of inspiratory resistive training. Pdi increased progressively from low to high intensity of threshold load training. The incremental changes in Pdi during threshold pressure training were significantly greater than those during inspiratory resistive training $(P<0.01)$ (Table 1$)$.

RMSdi\% progressively decreased during each intensity level of inspiratory resistive training. However, RMSdi\% increased obviously during threshold load training. (Table 1; Figure 6). RMSdi was statistically different between the two methods of IMT $(P<0.01)$.

Inspiratory time of participants progressively reduced during each intensity level of inspiratory resistive training while remaining the same during each intensity level of inspiratory threshold load training (Table 2).

The tidal volume $(\mathrm{Vt})$ and minute volume (Ve) of participants remained the same during each intensity level of both inspiratory resistive training and inspiratory threshold load training (Table 2). 


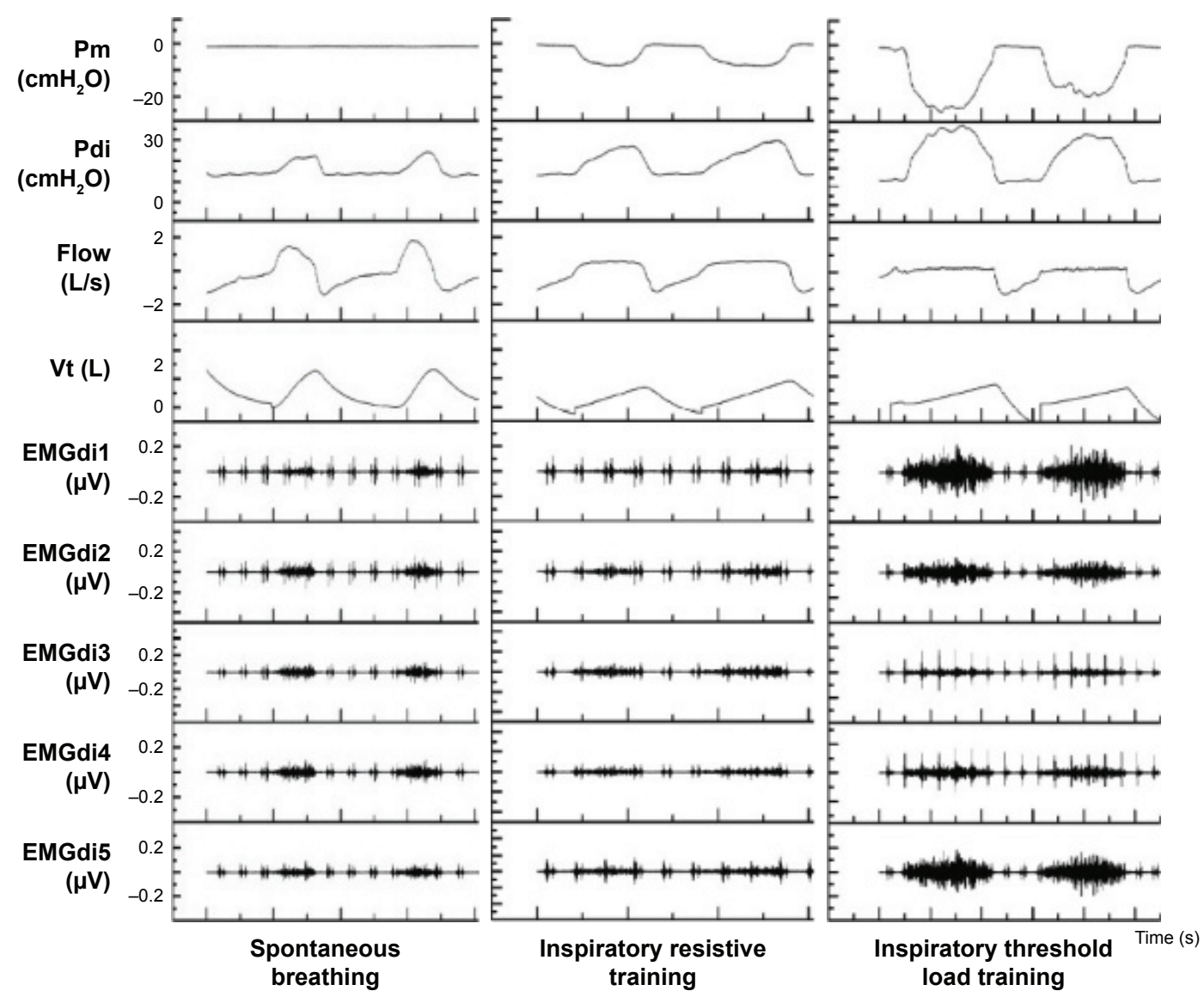

Figure 4 The waveforms of mouth pressure, diaphragmatic pressure, respiratory flow rate, tidal volume, and EMGdi of COPD patients during spontaneous breathing, respiratory resistance, and threshold load training.

Abbreviations: EMGdi, diaphragmatic electromyogram; Pm, mouth pressure; Pdi, transdiphragmatic pressure; $\mathrm{Vt}$, total volume.

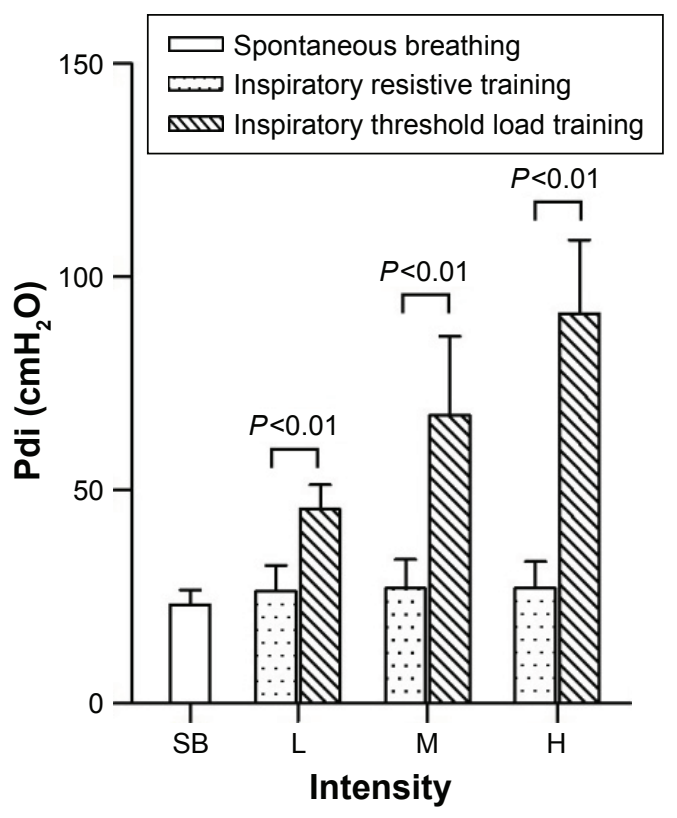

Figure 5 Pdi in 12 COPD patients during low-, moderate-, and high-intensity inspiratory resistance training and inspiratory threshold load training.

Abbreviations: Pdi, transdiaphragmatic pressure; SB, spontaneous breathing; L, low intensity; $\mathrm{M}$, moderate intensity; $\mathrm{H}$, high intensity.

\section{Discussion}

Skeletal muscle (including the diaphragm) sarcopenia is well documented as an important systemic manifestation of COPD, and it results from a systemic inflammatory condition. Furthermore, it has been suggested that reductions in functional performance are related to the muscle weakness present in these patients. ${ }^{18}$

The operation principles of the two inspiratory muscle trainers studied have great differences. The threshold trainer provides a constant, predetermined inspiratory load (generated by an adjustable built-in spring) during the entire inspiratory phase. It shows positive correlation between intensity of threshold load and length of the spring; therefore, intensity of threshold load can be determined objectively by adjusting the length of the built-in spring. And the threshold load is independent of the inspiratory flow rate. ${ }^{7}$ Inspiratory resistive trainers do not provide a constant inspiratory load to ensure the attainment of the inspiratory training intensity. ${ }^{8}$ Inspiratory resistive loading increased along with decrease in the 
Table I Result of diaphragmatic function test in 12 COPD patients during low-, moderate-, and high-intensity inspiratory resistive training and inspiratory threshold training

\begin{tabular}{|c|c|c|c|c|c|}
\hline \multirow[t]{2}{*}{ Parameters } & \multirow[t]{2}{*}{ Intensity } & \multicolumn{2}{|l|}{ Type of IMT } & \multicolumn{2}{|c|}{$P$-value } \\
\hline & & $\begin{array}{l}\text { Inspiratory } \\
\text { resistive } \\
\text { training }\end{array}$ & $\begin{array}{l}\text { Inspiratory } \\
\text { threshold } \\
\text { training }\end{array}$ & & \\
\hline \multirow[t]{3}{*}{$\mathrm{Pm}, \mathrm{cmH}_{2} \mathrm{O}$} & $\mathrm{L}$ & $-5.85 \pm 2.90$ & $-15.65 \pm 1.35$ & 0.00 & $* *$ \\
\hline & $M$ & $-8.29 \pm 3.45$ & $-29.74 \pm 3.95$ & 0.00 & $* *$ \\
\hline & $\mathrm{H}$ & $-9.50 \pm 3.71$ & $-38.83 \pm 6.11$ & 0.00 & $* *$ \\
\hline \multirow[t]{3}{*}{ Pes, $\mathrm{cmH}_{2} \mathrm{O}$} & $\mathrm{L}$ & $-10.83 \pm 3.12$ & $-21.67 \pm|.7|$ & 0.00 & $* *$ \\
\hline & $M$ & $-11.93 \pm 2.45$ & $-31.53 \pm 7.84$ & 0.00 & $* *$ \\
\hline & $\mathrm{H}$ & $-13.82 \pm 1.72$ & $-39.70 \pm 8.47$ & 0.00 & $* *$ \\
\hline \multirow[t]{3}{*}{ Pga, $\mathrm{cmH}_{2} \mathrm{O}$} & $\mathrm{L}$ & $17.33 \pm 3.80$ & $24.98 \pm 6.57$ & 0.00 & $* *$ \\
\hline & $M$ & $17.13 \pm 5.80$ & $37.63 \pm 13.22$ & 0.00 & $* *$ \\
\hline & $\mathrm{H}$ & $16.61 \pm 5.73$ & $54.05 \pm 15.14$ & 0.00 & $* *$ \\
\hline \multirow[t]{3}{*}{$\mathrm{Pdi}, \mathrm{cmH}_{2} \mathrm{O}$} & $\mathrm{L}$ & $26.48 \pm 5.85$ & $45.53 \pm 5.83$ & 0.00 & ** \\
\hline & $M$ & $27.10 \pm 6.68$ & $67.52 \pm 18.59$ & 0.00 & $* *$ \\
\hline & $\mathrm{H}$ & $27.24 \pm 6.13$ & $91.46 \pm 17.24$ & 0.00 & $* *$ \\
\hline \multirow[t]{3}{*}{ RMSdi\% } & $\mathrm{L}$ & $19.23 \pm 16.34$ & $36.89 \pm 19.09$ & 0.02 & $*$ \\
\hline & $M$ & $17.57 \pm \mid 4.87$ & $55.89 \pm 19.90$ & 0.00 & $* *$ \\
\hline & $\mathrm{H}$ & $17.26 \pm 14.65$ & $69.98 \pm 16.78$ & 0.00 & $* *$ \\
\hline
\end{tabular}

Notes: $* P<0.05$ inspiratory resistive training vs inspiratory threshold training; $* * P<0.01$ inspiratory resistive training vs inspiratory threshold training.

Abbreviations: IMT, inspiratory muscle training; L, low intensity; M, moderate intensity; H, high intensity; Pm, mouth pressure; Pes, esophageal pressure; Pga, intragastric pressure; Pdi, transdiaphragmatic pressure; RMSdi, root mean square of diaphragmatic electromyogram.

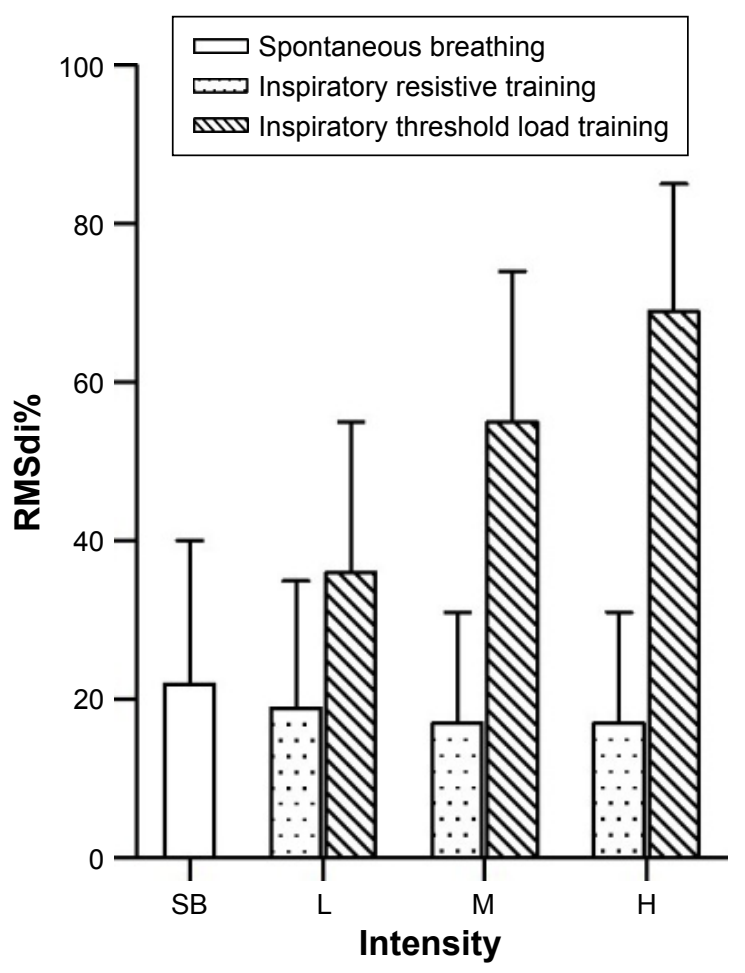

Figure 6 RMSdi\% in 12 COPD patients in low-, moderate-, and high-intensity inspiratory resistance training and inspiratory threshold load training.

Abbreviations: RMSdi, root mean square of diaphragmatic electromyogram; SB, spontaneous breathing; L, low intensity; $M$, moderate intensity; $H$, high intensity.
Table 2 Breathing mode in 12 COPD patients during low-, moderate-, and high-intensity inspiratory resistive training and inspiratory threshold training

\begin{tabular}{|c|c|c|c|c|c|}
\hline \multirow[t]{2}{*}{ Parameters } & \multirow[t]{2}{*}{ Intensity } & \multicolumn{2}{|l|}{ Type of IMT } & \multicolumn{2}{|c|}{$P$-value } \\
\hline & & $\begin{array}{l}\text { Inspiratory } \\
\text { resistive } \\
\text { training }\end{array}$ & $\begin{array}{l}\text { Inspiratory } \\
\text { threshold } \\
\text { training } \\
\end{array}$ & & \\
\hline \multirow[t]{3}{*}{$\mathrm{Ti}, \mathrm{s}$} & $\mathrm{L}$ & $2.20 \pm 1.17$ & $2.45 \pm 1.30$ & 0.08 & - \\
\hline & M & $3.18 \pm 0.80$ & $2.49 \pm 1.16$ & 0.02 & $* *$ \\
\hline & $\mathrm{H}$ & $4.92 \pm 1.27$ & $2.44 \pm 1.09$ & 0.00 & $* *$ \\
\hline \multirow[t]{3}{*}{ Ve, L } & $\mathrm{L}$ & $12.83 \pm 5.80$ & $|2.7| \pm 6.62$ & 0.96 & - \\
\hline & M & $11.10 \pm 4.03$ & $13.05 \pm 5.73$ & 0.20 & - \\
\hline & $\mathrm{H}$ & $9.51 \pm 4.37$ & $11.16 \pm 7.48$ & 0.46 & - \\
\hline \multirow[t]{3}{*}{$\mathrm{Vt}, \mathrm{L}$} & $\mathrm{L}$ & $0.8 I \pm 0.30$ & $0.85 \pm 0.40$ & 0.70 & - \\
\hline & M & $0.78 \pm 0.20$ & $0.88 \pm 0.47$ & 0.39 & - \\
\hline & $\mathrm{H}$ & $0.91 \pm 0.30$ & $0.94 \pm 0.29$ & 0.75 & - \\
\hline \multirow[t]{3}{*}{$\mathrm{Vt} / \mathrm{Ti}, \mathrm{L} / \mathrm{s}$} & $\mathrm{L}$ & $0.39 \pm 0.12$ & $0.37 \pm 0.19$ & 0.60 & - \\
\hline & M & $0.26 \pm 0.08$ & $0.37 \pm 0.14$ & 0.03 & $* *$ \\
\hline & $\mathrm{H}$ & $0.20 \pm 0.09$ & $0.4 I \pm 0.13$ & 0.00 & $* *$ \\
\hline \multirow[t]{3}{*}{$\mathrm{RR}, \mathrm{bpm}$} & $\mathrm{L}$ & $16.70 \pm 3.47$ & $16.03 \pm 3.35$ & 0.40 & - \\
\hline & M & $12.79 \pm 2.50$ & $16.03 \pm 3.48$ & 0.02 & $*$ \\
\hline & $\mathrm{H}$ & $9.67 \pm 3.21$ & $15.83 \pm 3.67$ & 0.00 & $* *$ \\
\hline
\end{tabular}

Notes: $* P<0.05$ inspiratory resistive training vs inspiratory threshold training; $* * P<0.01$ inspiratory resistive training vs inspiratory threshold training.

Abbreviations: bpm, breaths per minute; IMT, inspiratory muscle training; L, low intensity; M, moderate intensity; $\mathrm{H}$, high intensity; RR, respiratory rate; $\mathrm{Ti}$, inspiratory time; $\mathrm{Vt}$, total volume; $\mathrm{Ve}$, minute ventilation; $\mathrm{Vt} / \mathrm{Ti}$, mean inspiratory flow rate.

diameter of the inspiratory resistive hole; however, there was no correlation between the intensity of inspiratory resistive loading and the diameter of the inspiratory resistive hole, because inspiratory resistance is generated by inspiratory resistive trainers based on the inspiratory flow rate. Therefore, the resistance of inspiratory resistive trainers can be only adjusted by inspiratory levels.

\section{Respiratory mode}

Participants performed slow and deep breathing during inspiratory resistive training. It developed from the progressive rise of inspiratory time. Inspiratory time extended as the intensity of inspiratory resistance increased. In contrast, inspiratory time remained the same during different intensities of inspiratory threshold load training in COPD. It implied that the capacity of breathing mode adjustment reserve in COPD patients ${ }^{19}$ and the respiratory mode response toward various IMT devices is different.

\section{Respiratory flow and volume}

The tidal volume and minute volume of participants remained the same when performing different levels of inspiratory resistive training and inspiratory threshold load training. 
It implied that neural respiratory drive takes effort to regulate the breathing pattern in order to maintain proper ventilation. Ventilation was maintained consistently to satisfy the requirement of metabolic activity during both inspiratory resistive or threshold load training. It reflected the strong capacity of coping with various respiratory abnormal circumstances. ${ }^{20}$ The mean inspiratory flow rate diminishes as the intensity of inspiratory resistance increased: $Q$ (quantity of flow $)=\Delta P($ difference of pressure $) / R$ (resistance $)$, according to Poiseuille's law. ${ }^{21}$ Inspiratory flow downregulated to prevent the pressure difference of airway from increasing. ${ }^{22}$ It showed that the first impulse of the neural respiratory drive is to minimize the pressure difference in the airway by adjusting the breathing mode.

Different intensities of inspiratory threshold load training had no effect on the mean inspiratory flow rate of participants. The fluid mechanics of threshold load training does not conform to Poiseuille's Law. Inspiratory valve is opened and flow is generated only when the mouth pressure is greater than the inspiratory load. Therefore, the load in the inspiratory threshold load training procedure is steady during the whole inspiratory period. The neural respiratory drive failed to adjust the inspiratory flow rate during inspiratory threshold training. The first response of the respiratory drive is enlarging the inspiratory effort to resist the inspiratory load.

\section{Respiratory pressure}

The absolute value of the mouth pressure approached zero during spontaneous breathing in healthy subjects. Absolute values of esophageal pressure and intragastric pressure progressively increased during inspiratory resistive training. Mouth pressure increased as the inspiratory resistance increased. The Pdi value remained the same during different levels of inspiratory resistive training. It supported the hypothesis that the neural respiratory drive would not withstand inspiratory resistance using the force reserves of the diaphragm. Conversely, the respiratory center minimized the diaphragm force by extending the inspiratory period and diminishing the inspiratory flow rate.

Mouth pressure reaction toward inspiratory threshold load training is different from that to inspiratory resistive training. The absolute value of mouth pressure linearly increased during inspiratory threshold load training. The value of mouth pressure was equal to the parallel inspiratory threshold load. The variation of mouth pressure during inspiratory threshold load training was greater than that during inspiratory resistive training. The variation of esophageal pressure, intragastric pressure, and Pdi followed the trend of mouth pressure.
It supported the fact that respiratory muscle strength can be mobilized substantially with inspiratory threshold load training. Greater diaphragmatic strength was mobilized to initiate the inspiratory flow along with increased inspiratory load.

The predetermined inspiratory load was individualized and it depended on the MIP value during inspiratory threshold load training. The MIP of COPD patients is much smaller than that of healthy subjects. Therefore, the intensity of threshold load in COPD patients is smaller than that in healthy people. The characteristic of mouth pressure variation in COPD patients was a linear decline during each intensity level of threshold load training. The absolute values of Pes, Pga, and Pdi of COPD patients increased as the inspiratory threshold load was raised but did not conform to a linear rise. COPD patients have high reaction sensitivity of diaphragmatic pressure according to the variation of the Pdi in inspiratory threshold load training. The variation of intragastric pressure of COPD patients was greater during inspiratory threshold load training. It indicated that the breathing mode of COPD patient was converted to abdominal breathing easily during inspiratory threshold load training. Therefore, inspiratory threshold load training can be considered as one of abdominal breathing training. COPD patients had the ability to reach favorable ventilation without raising the Pdi in inspiratory resistance. Inspiratory muscle was not given enough practice in COPD patients during inspiratory resistance training. Conversely, diaphragmatic strength in COPD could be mobilized during the inspiratory threshold load training. Therefore, participants could reach the training intensity more easily in inspiratory threshold load training than in inspiratory resistance training.

\section{Neural respiratory drive}

RMSdi\% of COPD patients decreased during inspiratory resistive training; however, it increased during inspiratory threshold load training. It is the impulse to shorten the inspiratory flow rate in COPD to avoid the inspiratory resistance and increase in diaphragmatic force. Furthermore, diaphragmatic electrical activity and Pdi generation are coupled processes. Deep and slow breathing mode prevented diaphragmatic mobilization and respiratory center drive activity from increasing simultaneously. These variations of neural respiratory drive are to minimize the incidence of diaphragmatic fatigue during improper breathing mode in COPD.

RMSdi\% of COPD patients increased obviously in inspiratory threshold load training. Respiratory additional load and mouth pressure are stable in inspiratory threshold load training. Therefore, participants failed to change the breathing resistance to reduce the respiratory additional load. 
Conversely, inspiratory flow is generated only when the respiratory strength exceeds the additional threshold load. Participants had to mobilize diaphragmatic force to withstand the threshold load and produce inspiratory flow for ventilation. Therefore, the neural respiratory drive increased in order to generate more diaphragmatic pressure during inspiratory threshold load training.

Some limitations of this study are as follows: 1) lack of patients' follow-up after completion of the study; 2) the lack of a double-blind design; and 3) the number of female subjects (for cultural reasons, the prevalence of smoking is very low among women).

\section{Conclusion}

The Pdi and neural respiratory drive of patients with COPD was much greater in inspiratory threshold load training than in inspiratory resistive training. It implied that high-intensity inspiratory threshold load training had a greater effect on diaphragmatic mobilization than inspiratory resistive training in COPD. These findings suggest that inspiratory threshold load training might be superior to inspiratory resistive training in pulmonary rehabilitation of COPD.

\section{Acknowledgments}

We thank Xiao-cong Li for contributing to the recruitment of healthy controls and COPD patients in this study. We also thank Wallace Lee, Director of Celki VitalAire Company, for assisting us in purchase of inspiratory training devices - inspiratory resistive trainers ${ }^{\circledR}$ and inspiratory threshold trainers ${ }^{\circledR}$.

\section{Author contributions}

$\mathrm{RC}$ and LZ contributed to study conception and design. WW and XZ drafted the submitted article and revised the draft critically for important intellectual content. RC and LZ contributed to revision of the draft critically for important intellectual content and provided final approval of the version to be published. LL, YO, and XL contributed to acquisition, analysis, and interpretation of data, in addition to drafting the submitted article. LG and BG contributed to acquisition of data, analysis and interpretation of data, as well as contributed to revising the draft critically for important intellectual content. All authors contributed toward data analysis, drafting and critically revising the paper and agree to be accountable for all aspects of the work.

\section{Disclosure}

The authors report no conflicts of interest in this work.

\section{References}

1. Global Initiative for Chronic Obstructive Lung Disease. Global Strategy for the Diagnosis, Management and Prevention of Chronic Obstructive Pulmonary Disease (updated 2016). Bethesda: National Heart, Lung and Blood Institute; 2016.

2. Spruit MA, Singh SJ, Garvey C, et al; ATS/ERS Task Force on Pulmonary Rehabilitation. An official American Thoracic Society/European Respiratory Society Statement: key concepts and advances in pulmonary rehabilitation. Am J Respir Crit Care Med. 2013;188(8):e13-e64.

3. Polkey MI, Kyroussis D, Hamnegard CH, Mills GH, Green M, Moxham J. Diaphragm strength in chronic obstructive pulmonary disease. Am J Respir Crit Care Med. 1996;154(5):1310-1317.

4. Killian KJ, Jones NL. Respiratory muscles and dyspnea. Clin Chest Med. 1988;9(2):237-248.

5. Hamilton AL, Killian KJ, Summers E, Jones NL. Muscle strength, symptom intensity, and exercise capacity in patients with cardiorespiratory disorders. Am J Respir Crit Care Med. 1995;152(6 pt 1): 2021-2031.

6. Heijdra YF, Dekhuijzen PN, van Herwaarden CL, Folgering HT. Nocturnal saturation and respiratory muscle function in patients with chronic obstructive pulmonary disease. Thorax. 1995;50(6):610-612.

7. Gosselink R, De Vos J, van den Heuvel SP, Segers J, Decramer M, Kwakkel G. Impact of inspiratory muscle training in patients with COPD: what is the evidence? Eur Respir J. 2011;37(2):416-425.

8. Jolley CJ, Luo YM, Steier J, et al. Neural respiratory drive in healthy subjects and in COPD. Eur Respir J. 2008;33(2):289-297.

9. Chen RC, Que CL, Yan S. Introduction to a new inspiratory threshold loading device. Eur Respir J. 1998;12(1):208-211.

10. Chen RC, Yan S. Perceived inspiratory difficulty during inspiratory threshold and hyperinflationary loadings. Am J Respir Crit Care Med. 1999;159(3):720-727.

11. American Thoracic Society/European Respiratory Society. ATS/ERS statement on respiratory muscle testing. Am J Respir Crit Care Med. 2002;166(4):518-624.

12. Supinski GS, Westgate $P$, Callahan LA. Correlation of maximal inspiratory pressure to transdiaphragmatic twitch pressure in intensive care unit patients. Crit Care. 2016;20(1):77.

13. Lindström L, Magnusson R. Interpretation of myoelectric power spectra: a model and its applications. Proc IEEE. 1977;65:653-662.

14. Luo YM, Chen RC, Zhong NS. [Measurement of diaphragm compound muscle action potential with magnetic stimulation of the phrenic nerve and multipara esophageal electrode in intensive care unit]. Zhonghua Jie He He Hu Xi Za Zhi. 2005;28(8):505-508. Chinese.

15. Garland AJ, Doshi A, Turcanu V. Neural respiratory drive measurement for COPD assessment and monitoring. Pneumologia. 2015; 64(1):14-17.

16. John AE, William AW. The assessment of maximal respiratory mouth pressures in adults. Respir Care. 2009;54(10):1348-1359.

17. Beacham J, Barnes SM, Walker W, Morse HG. Inspiratory resistance training for pulmonary rehabilitation. Chest. 1989;96(3):698-699.

18. Butcher SJ, Meske JM, Sheppard MS. Reductions in functional balance, coordination, and mobility measures among patients with stable chronic obstructive pulmonary disease. J Cardiopulm Rehabil. 2004;24(4):274-280.

19. Breslav IS, Klement RF, Kochubeev AV. [Functional and diagnostic significance of a study of respiratory regulation in patients with chronic nonspecific lung diseases]. Ter Arkh. 1987;59(12):44-48. Russian.

20. Kinkead R. The periaqueductal grey and its role in respiratory regulation. Acta Physiol (Oxf). 2014;211(3):474-475.

21. Schreuder MF, Koster-Kamphuis L. Poiseuille's law in polyuria. Pediatr Nephrol. 2014;29(7):1289.

22. Han DM. [Upper-airway obstructive diseases related to braincardiovascular and metabolic consequence]. Zhonghua Er Bi Yan Hou Tou Jing Wai Ke Za Zhi. 2008;43(3):161-162. Chinese. 
International Journal of COPD

\section{Publish your work in this journal}

The International Journal of COPD is an international, peer-reviewed journal of therapeutics and pharmacology focusing on concise rapid reporting of clinical studies and reviews in COPD. Special focus is given to the pathophysiological processes underlying the disease, intervention programs, patient focused education, and self management protocols.

This journal is indexed on PubMed Central, MedLine and CAS. The manuscript management system is completely online and includes a very quick and fair peer-review system, which is all easy to use. Visit http://www.dovepress.com/testimonials.php to read real quotes from published authors 